\title{
Um estudo com Foco na Forma (IFF): o presente do subjuntivo em espanhol ${ }^{1}$
}

\section{A case of Form-Focused Instruction (FFI): the present subjunctive in Spanish}

\author{
Gisele Benck de Moraes* \\ Universidade de Passo Fundo \\ Passo Fundo - Rio Grande do Sul / Brasil
}

\begin{abstract}
RESUMO: Este estudo investigou como estudantes brasileiros desenvolvem seu aprendizado no que concerne ao presente do subjuntivo em espanhol, principalmente quando utilizam as conjunções cuando, aunque e donde. A pesquisa foi aplicada com estudantes, de nível intermediário, em uma instituição privada do interior do Estado do Rio Grande do Sul. Como base teórica foi utilizada a IFF com ênfase nas ideias de Spada $(1997,2008,2010)$ e Ellis (2001, 2006, 2009). Foram quatro etapas de pesquisa: pré-teste; aulas-tratamento; pós-teste imediato e pós-teste postergado. Para as tarefas orais e escritas foram utilizados como recursos a Plataforma Edmodo e o Programa Team Speak. Durante a análise dos dados foi possível perceber o equívoco existente e o quanto a IFF foi benéfica para a aprendizagem do presente do subjuntivo em espanhol. PALAVRAS-CHAVE: espanhol; instrução com foco na forma; presente do subjuntivo; Lingua Estrangeira.
\end{abstract}

\begin{abstract}
This study investigated how Brazilian students develop their learning with regard to the present subjunctive in Spanish, particularly when they use the conjunctions cuando, aunque, and donde. The research was applied to intermediate students at a private institution in the state of Rio Grande do Sul. Form-Focused Instruction (FFI) was applied as the theoretical framework, with an emphasis on the ideas of Spada $(1997,2008,2010)$ and Ellis $(2001$, 2006, 2009). The research included four stages: pre-test, remedial lessons, immediate post-test, and delayed post-test. The Edmodo Platform and Team Speak Program were used as tools for oral and written assignments. Data analysis
\end{abstract}

\footnotetext{
*gbenck@upf.br.

${ }^{1}$ Artigo resultante da tese de doutorado intitulada "A aprendizagem do presente do subjuntivo do espanhol por alunos brasileiros: um estudo com foco na forma", defendida em outubro de 2014 e orientada pela professora Dra. Marília dos Santos Lima.
} 
illustrated the ongoing misunderstanding and how much FFI was beneficial for learning the present subjunctive in Spanish.

KEYWORDS: Spanish; form-focused instruction; present subjunctive; foreign language.

\section{Introdução}

Nos estudos sobre a aquisição do espanhol como Língua Estrangeira $\left(\mathrm{LE}^{2}\right)$, em distintos contextos de ensino, os resultados apontam para alguns obstáculos encontrados por brasileiros no que se refere à aprendizagem de formas linguísticas, em alguns níveis, a saber: lexical (VILLALBA, 2002) e morfossintático (BOÉSSIO, 2003; COSTA, 2004).

Além disso, outro aspecto linguístico que parece resultar difícil aos falantes do português brasileiro, como aprendizes de espanhol, é o presente do subjuntivo. Temos verificado, como professores de ensino superior, no curso de Letras, que os alunos de espanhol não empregam adequadamente a forma verbal presente do subjuntivo em orações subordinadas adverbiais, como no caso de Cuando + presente de subjuntivo + futuro imperfecto de indicativo (Cuando viaje, compraré muchos regalos), com ideia de futuro, uma vez que existe a tendência de emprego de infinitivo flexionado, em vez do presente do subjuntivo. Além disso, observamos que os alunos, mesmo em estágio final de conclusão do curso de Letras, apresentam construções como: "Cuando yo entrar, hablaré contigo", em vez de "Cuando yo entre, hablaré contigo". Logo, existe a tendência de o aprendiz utilizar o infinitivo pessoal, como acontece no português brasileiro, ou seja, o emprego do verbo no infinitivo com a marca de pessoa do discurso em oraçóes temporais, conforme já foi constatado por Boéssio (2003).

Neste estudo, investigamos a aquisição do presente do subjuntivo, mais especificamente em orações subordinadas adverbiais, com cuando, aunque e donde, em produçōes orais e escritas de universitários brasileiros aprendizes de espanhol no curso de Letras, de nível intermediário ${ }^{3}$, de uma universidade privada do estado do Rio Grande do Sul. Nosso estudo estará baseado em conceitos de Spada (1997, 2008, 2010) e Ellis (1997, 2001, 2006, 2009). Adotamos a perspectiva teórica de instrução com foco na forma

\footnotetext{
${ }^{2}$ Neste estudo, as expressões língua estrangeira (LE) e segunda língua são usadas indistintamente no que se refere ao processo de aquisição da língua alvo.

${ }^{3}$ Nível no qual os participantes se encontram, de acordo com a instituição de ensino.
} 
de Spada (1997a, p. 73), que a define como "qualquer esforço pedagógico usado para chamar a atenção do aluno para a forma de maneira explícita ou implícita"4.

Por fim, a presente investigação pode auxiliar na melhoria da habilidade de expressão oral e escrita dos aprendizes deste estudo em relação à aplicação da forma em exame, visto que as produções dos aprendizes estarão baseadas tanto no sentido quanto na norma da língua-alvo.

\section{0 foco na forma no ensino de língua estrangeira}

O ensino ou a instrução com foco na forma (IFF) é uma perspectiva que oportuniza o uso da língua-alvo em situações significativas (cf. DOUGHTY; WILLIAMS, 1998), isto é, em contexto em que os alunos precisem utilizar a língua de maneira real ou simulada.

Como já referido na introdução, Spada (1997a) define foco na forma como "qualquer esforço pedagógico que é usado para chamar a atenção do aluno para a forma de maneira explícita ou implícita"s. A autora também afirma que "foco na forma pode se dar através do ensino direto da língua, como, por exemplo, do ensino de regras gramaticais, ou através de reaçóes aos erros dos aprendizes"6 (p. 73).

Por outro lado, Ellis $(2001$, p. 2) define instrução com foco na forma como "qualquer atividade instrucional, planejada ou incidental, que procura induzir os aprendizes de uma língua a prestar atenção à forma linguística” $\mathrm{O}$ autor também defende que seria mais apropriado dividir a IFF em três tipos de instrução, que seriam: foco nas formas, foco na forma planejado e foco na forma incidental. A primeira caracteriza-se pela consciência do professor e dos alunos de que o principal foco é a forma linguística. A intervenção pode ser feita, de acordo com o autor, explícita (como uma regra que se tenha em mente) ou implicitamente (memorizando exemplos e inferindo regras). Na prática pedagógica, o foco nas formas pode ser obtido por meio da

\footnotetext{
4 "Will mean any pedagogical effort which is used to draw the learners' attention to language form either implicitly or explicitly".

5 "Will mean any pedagogical effort which is used to draw the learners' attention to language form either implicitly or explicitly".

6 "This can include the direct teaching of language and/or reactions to learners' errors". 7 "Any planned or incidental instructional activity that is intended to induce language learners to pay attention to linguistic form".
} 
apresentação de insumo estruturado ao aluno, que seriam amostras da língua preparadas para oferecer, repetidamente, exemplos da estrutura alvo, ou da prática produtiva, que exige que o aprendiz utilize formas já armazenadas.

O segundo tipo de instrução, planejado, para Ellis (2001), seria praticado de maneira intensiva pelos aprendizes, o que significa que poderiam ter a oportunidade de utilizar uma única estrutura preestabelecida diversas vezes. Os exemplos dados pelo autor são o insumo enriquecido, ou seja, a amostra da língua, utilizada em contexto comunicativo, modificada para apresentar maior quantidade de exemplos da estrutura, e as tarefas de comunicação focalizadas, que provocam a produção de um aspecto gramatical alvo.

O terceiro tipo de instrução, com foco na forma incidental, por sua vez, é definido como extensivo, uma vez que procura abranger uma série de formas linguísticas. Segundo o autor, há duas opçōes para o desenvolvimento desse tipo de instrução em sala de aula. A primeira delas seria o foco na forma planejado, no qual uma forma problemática é priorizada mesmo quando não há dificuldades de comunicação ou erro linguístico. A segunda opção é o foco na forma reativo, que, ao contrário do anterior, é originado por um erro linguístico, podendo acontecer como feedback implícito ou explícito. Ellis (2001) sugere que esse último tipo de instrução é o mais efetivo, uma vez que aparece da necessidade real de comunicação e para solucionar mal entendidos.

Nesta investigação, utilizamos a aprendizagem explícita, seja durante a aplicação dos testes ou do tratamento aplicado à turma, mesmo que alguns testes também permitam a utilização do aprendizado implícito. Dekeyser (2003) define o aprendizado implícito como "aprendizado sem consciência do que está sendo aprendido" (p. 314), e aprendizado explícito como "ensino de regra gramatical, quando os alunos são estimulados a encontrar regras por si próprios" ${ }^{\prime \prime}$ (p. 314). O autor também acredita que o conhecimento aprendido pode tornar-se implícito no caso em que os aprendizes possam perder a consciência da estrutura com o tempo. Isso pode ser relacionado com o objeto de estudo, presente do subjuntivo, principalmente com o uso da conjunção cuando, pois os alunos de nível intermediário, que supostamente já tenham aprendido esse conteúdo, com o passar do tempo

\footnotetext{
8 "learning without awareness of what is being learn".

9 "teaching grammar rule, when students are encouraged to find rules for themselves".
} 
perdem a consciência do uso e voltam a utilizar o infinitivo. E, em outros momentos, os aprendizes, segundo Dekeyser (2003), podem tornar-se mais conscientes da estrutura de conhecimento implícito quando tentam acessálo, por exemplo, para aplicá-la em um novo contexto.

Segundo Mitchell, Myles e Marsden (2013), quando a relação de forma e significado é clara e uniformemente codificada no insumo, o aprendiz descobrirá outras relaçôes de forma e significado e irá incorporá-la mais consistentemente dentro de seu sistema de interlíngua ${ }^{10}$. De acordo com as autoras, a codificação clara e transparente do aspecto linguístico no insumo força o aprendiz a descobrir a relação entre forma e significado.

Dekeyser (2003) sugere que há um papel positivo para algum tipo de atenção à forma, ou seja, através do ensino explícito de gramática e da correção explícita do erro. A classificação de correção do erro foi baseada na definição de Dekeyser (1995) de que um tratamento instrucional é explícito se as regras de explicação da forma partem da instrução (dedução) ou se for solicitado aos aprendizes atender a formas particulares e tentarem encontrar as regras por si próprios (indução). Quando nem a apresentação da regra nem as direções atenderem às formas particulares de um tratamento, aquele tratamento será considerado implícito (NORRIS; ORTEGA, 2000). Reiteramos que nesta investigação foi dada atenção ao tratamento explícito, mais precisamente por meio da explicação a partir da instrução.

Para Roher (2008), o conhecimento explícito não é sempre o resultado ou causa de aprendizado explícito e também pode derivar do aprendizado implícito ou proficiência aumentada. Para o referido autor, o aprendizado explícito pode ser definido como "quando o aprendiz tem consciência real formulando e testando hipóteses conscientes no curso do aprendizado"11 (p.69).

Doughty e Williams (1998) sugerem que a intervenção pedagógica explícita tenha três aspectos distintivos: (1) antes da atenção dos aspectos linguísticos, o aprendiz deve trabalhar com o sentido e é necessário que haja a certificação de que as formas alvo sejam pelo menos naturais para que a tarefa possa ser completada; (2) os aspectos linguísticos para a instrução devem ser escolhidos por meio de uma análise das necessidades dos aprendizes, feita de maneira reativa ou proativa; e (3) o tratamento deve ser breve e

${ }^{10}$ Língua do aprendiz.

11 "When the learner has online awareness, formulating and testing conscious hypotheses in the course of learning". 
evidente, garantindo, consequentemente, que este não obstrua a atividade comunicativa principal, mas, ao mesmo tempo, seja evidente para o aprendiz.

Esses aspectos são complementados e reafirmados com o que diz Júnior (2010): "há efeitos positivos na instrução explícita e esses efeitos são duráveis" (p. 747). Ou seja, a instrução com foco na forma explícita traz benefícios para a aprendizagem, neste caso mais especificamente para a aprendizagem do presente do subjuntivo em espanhol.

Além das definições de IFF, das maneiras para chamar a atenção do aprendiz para a forma (explícita/implicitamente; planejada/incidental) e as suas implicações na sala de aula, apresentamos o tempo de instrução como fator relevante, segundo Spada e Lightbown (2008).

Spada e Lightbown (2008) asseveram que há um consenso de que a instrução com foco na forma ajuda os aprendizes a aprender aspectos da língua-alvo. Mais especificamente, o artigo compara o papel da IFF em lições que são isoladas da interação comunicativa ou baseadas em conteúdo como aquela em que a IFF é integrada dentro de atividades em que a ênfase primordial permanece no significado.

Segundo Spada e Lightbown (2008), IFF isolada é a provisão da instrução em lições cuja proposta primária é ensinar os alunos sobre um aspecto particular da língua porque o professor acredita que os alunos, provavelmente, não adquirem o aspecto durante atividades comunicativas sem uma oportunidade para aprender sobre o objeto linguístico em uma situação onde sua forma e significado possam ser esclarecidos.

Dessa forma, a IFF integrada, de acordo com as autoras, ocorre em atividades em sala de aula durante as quais o foco principal permanece no significado, em que o feedback ${ }^{12}$, isto é, um tratamento do erro que tem o propósito de auxiliar os aprendizes a perceberem lacunas entre sua interlíngua e a língua-alvo, ou explicações breves são oferecidas para ajudar os alunos a expressarem significado dentro da interação comunicativa, e, como resultado, pode orientá-los a reestruturar sua gramática.

Spada e Lightbown (2008) sugerem que ambas as instruções, isolada e integrada, podem ser benéficas dependendo do aspecto da língua a ser aprendido, bem como as características do aprendiz e as condições de

\footnotetext{
${ }^{12}$ Vários estudos, entretanto, apontam para o fato de que os professores nem sempre têm o conhecimento especializado sobre o assunto para maximizar as oportunidades desse evento interacional (LIMA; BORBA, 2004, p. 266).
} 
aprendizado. Por exemplo, lições isoladas podem ser necessárias para ajudar os aprendizes que compartilham a mesma língua materna a superar problemas relacionados à influência de LM na sua interlíngua. Em comparação, em contextos de ensino integrado, é o modelo instrucional que tem maior potencial para facilitar o desenvolvimento da fluência e acurácia de língua, que está disponível para o uso fora da sala de aula. As autoras concordam ainda com Dekeyser (1998), que, em sua crítica da técnica repetitiva no ensino de língua audiolingual, comentou que a prática tem valor para o aprendizado da língua quando ela envolve prática em "transmitir significados pessoais" (p. 53-54).

Neste estudo, corroboramos com a ideia de que ambas as instruções (isolada e integrada) podem ser benéficas para o ensino do presente do subjuntivo em espanhol sob o enfoque da IFF.

\section{As tarefas para instrução com foco na forma}

Um dos recursos que pode facilitar a aprendizagem do presente do subjuntivo é o ensino através de tarefas, pois a tarefa é concebida como uma atividade contextualizada que requer dos aprendizes o uso da língua efetivamente, com ênfase no significado e com uma conexão ao mundo real, a fim de alcançar um objetivo proposto.

Adotamos, neste estudo, os critérios de Norris e Ortega (2001) e de Ellis $(2006,2009)$ para a elaboração das tarefas na execução da pesquisa.

Norris e Ortega (2001) e Ellis (2006, 2009) preconizam a utilização das tarefas focadas, uma vez que fornecerão oportunidades para a comunicação utilizando um aspecto específico da língua, no caso o presente do subjuntivo. Ao pensarmos tarefas focadas, estaremos contemplando os quatro critérios citados acima: uso natural da língua-alvo; concentração; foco na forma; tipo de tarefa.

O ensino de língua baseado em tarefa como outros tipos de ensino de língua implica tanto no planejamento quanto na metodologia. Ou seja, as decisões devem ser tomadas considerando quais tipos de tarefas devem ser incluídos em um curso, qual será o conteúdo das tarefas e crucialmente como dar sequência às tarefas de modo a facilitar o aprendizado. As decisões metodológicas afetam como estruturar uma lição baseada em tarefa e qual tipo de estrutura empregar. Uma aula baseada em tarefa pode envolver três fases (fase de pré-tarefa, a fase principal da tarefa e a fase da pós-tarefa), embora apenas uma delas (a fase principal da tarefa) seja obrigatória. As 
tarefas podem ser realizadas em um contexto coletivo de sala de aula, em pares, em grupos ou individualmente.

Um dos objetivos do ensino de língua baseado em tarefa é de fato criar contextos em que os aprendizes possam vivenciar o que significa comunicarse em diferentes estágios de seu desenvolvimento - usando quaisquer recursos à sua disposição. Inevitavelmente, com iniciantes, as interaçōes serão limitadas, mas isso não significa que elas não sejam de valor pedagógico.

Esse objetivo de ensino converge com o que pensa Littlewood (1996). Segundo o autor, cada tipo de tarefa deve desempenhar seu próprio papel para ajudar os estudantes a desenvolverem tanto a naturalidade na hora da atuação como deixar clara a compreensão ao usar o sistema linguístico da língua-alvo. Em cada tipo de atividade, as formas linguísticas podem estar mais ou menos relacionadas com a função comunicativa e com a realidade não linguística.

Assim, nesta investigação, tarefas são entendidas como atividades pedagógicas especialmente planejadas que os alunos realizarão para a aprendizagem do presente do subjuntivo. As tarefas escritas foram pensadas de acordo com Norris e Ortega (2001): teste de preenchimento de lacunas; teste de múltipla escolha; descrição de imagem e criação de história, conforme quadro1:

Quadro 1: Tarefas escritas

\begin{tabular}{|l|l|l|}
\hline Tipo de tarefa escrita & Tipo de conhecimento & Tipo de ferramenta \\
\hline Teste de lacunas & Conhecimento explícito & Não digital \\
\hline Teste de múltipla escolha & Conhecimento explícito & Plataforma Edmodo \\
\hline Descrição de imagem & Conhecimento implícito/explícito & Não digital \\
\hline Criação de uma história & Conhecimento implícito/explícito & Plataforma Edmodo \\
\hline
\end{tabular}

As tarefas orais foram pensadas de acordo com Norris e Ortega (2001) e Ellis (2006, 2009): perguntas controladas; descrição de imagem e criação de história, conforme quadro 2 : 
Quadro 2: Tarefas orais

\begin{tabular}{|l|l|l|}
\hline Tipo de tarefa oral & Tipo de conhecimento & Tipo de ferramenta \\
\hline Perguntas controladas & Conhecimento explícito & Programa Tem Speak \\
\hline Descrição de imagem & Conhecimento implícito/ explícito & Programa Tem Speak \\
\hline Criação de uma história & Conhecimento implícito/ explícito & Programa Tem Speak \\
\hline
\end{tabular}

A seguir, apresentaremos a pesquisa realizada e os resultados obtidos.

\section{0 contexto e os procedimentos da pesquisa}

Este estudo foi realizado em uma turma de nível intermediário, VI nível, de um curso de Letras - Espanhol, em uma universidade privada do interior do Rio Grande do Sul.

Segundo André (2004), um estudo investigativo precisa levar em consideração a história pessoal de cada participante, assim como as condições específicas em que se dá a apropriação dos conhecimentos.

Assim, podemos dizer que os participantes, 12 no geral, com idades entre 18 e 40 anos, em sua grande maioria, provêm de cidades do interior do Rio Grande do Sul e, para que pudessem participar da investigação, assinaram um termo de consentimento esclarecido e preencheram uma ficha individual, na qual era possível identificar os perfis específicos de cada participante.

Um dos requisitos para a participação na pesquisa era que os alunos não tivessem tido contato direto com a língua espanhola antes do ingresso na universidade, não tivessem participado de intercâmbios acadêmicos ou realizado viagens de estudo em países de fala espanhola.

Para a realização da pesquisa, no período de instrução explícita, foram aplicados os testes (pré-teste; pós-teste imediato; pós-teste postergado), foram utilizadas como instrumento para a coleta de dados também as ferramentas Team Speak e a Plataforma Edmodo, sem que os alunos estivessem conscientes do foco da investigação.

Em todas as etapas de obtenção de dados da investigação (pré-teste, pósteste imediato, pós-teste postergado) foram utilizadas atividades de preencher lacunas, testes de múltipla escolha, descrição de imagem e criação de uma história, os quais já foram referidos anteriormente e serão detalhados a seguir.

Imediatamente após a aplicação do pré-teste, durante a intervenção pedagógica da investigadora e da professora titular, foram ministradas 
duas aulas sobre o ensino do presente do subjuntivo sob o enfoque da IFF, totalizando oito horas/aula para o tratamento específico e a aplicação de tarefas para esse fim.

Em seguida, a professora participante aplicou as tarefas como instrumentos (pós-teste imediato e pós-teste postergado) para verificar os efeitos da IFF.

As tarefas selecionadas e elaboradas foram escolhidas tendo como base os estudos de Norris e Ortega (2001), pois esses autores utilizaram os seguintes tipos de atividade que possibilitavam categorizar os seguintes tipos de resultados: a) julgamentos metalinguísticos; b) respostas selecionadas; c) respostas construídas; d) respostas construídas livremente.

As tarefas selecionadas para este estudo oportunizarão à pesquisadora analisar os efeitos do tipo de instrução (explícita e implícita) em relação a aspectos linguísticos (simples e complexos), mas especificamente, quanto ao uso de cuando com valor de futuro; aunque e donde e quanto ao uso do presente do subjuntivo, e as medidas de resultado (controladas e livres).

Essas tarefas, novamente, foram selecionadas e elaboradas tendo como base os estudos de Norris e Ortega (2001) e de Ellis (2006). As tarefas de escrita livre, como atividades de criação de histórias; tarefas de descrição de imagem e/ou tarefas de olhar a imagem e preencher as lacunas, são atividades que têm desde um caráter mais controlado a um menos controlado, pois geram um desafio maior e uma autonomia do aluno ao realizar a atividade. Já as atividades específicas de perguntas controladas e transformação de oraçōes são tarefas monitoradas, controladas pela professora e pela pesquisadora, as quais verificaram especificamente o uso do objeto de estudo em questão.

Nas tarefas orais, também foram analisados os efeitos do tipo de instrução mencionado anteriormente, $\mathrm{o}$ aspecto gramatical e as medidas de resultado.

\subsection{O uso de cuando, aunque e donde no presente do subjuntivo em espanhol}

Para a elaboração dos dados quantitativos, utilizamos o Programa GOLDVARB-X, que consiste na ferramenta mais recente da série VARBRUL, ${ }^{13}$ e foi desenvolvido por Sankoff, Tagliamonte e Smith (2005).

\footnotetext{
${ }^{13}$ Aplicativo para Windows e Macintosh, disponível em: http://individual.utoronto. $\mathrm{ca} /$ tagliamonte/goldvarb.htm
} 
O programa GOLDVARB-X possibilita análises estatísticas apuradas do efeito exercido por cada uma das variáveis, sejam elas linguísticas ou extralinguísticas, sobre a regra variável em exame. O programa oferece duas modalidades de análise dos dados: a análise binomial one-step, na qual analisa todos os grupos e células simultaneamente, e a análise binomial step-up/stepdown, na qual a análise é frequentemente utilizada em estudos linguísticos (TAGLIAMONTE, 2006).

Para uma melhor organização, privilegiamos a análise pela ordem de discussão dos dados e não pela ordem de seleção do programa, que segue: rodada geral (variáveis linguísticas e sociais); rodada amalgamada e rodada com cruzamento.

Para esse estudo, foram determinadas algumas variáveis ${ }^{14}$ específicas para fins de análise: variável tipo de prática; variável etapa de coleta; variável tipo de atividade; variável tipo de habilidade; variável tipo de conjunção.

\subsubsection{Frequência global}

A seguir, apresentamos o Gráfico 1, que indica a aplicação total do presente do subjuntivo do espanhol em orações subordinadas, bem como a sua não aplicação.

\section{Gráfico 1}

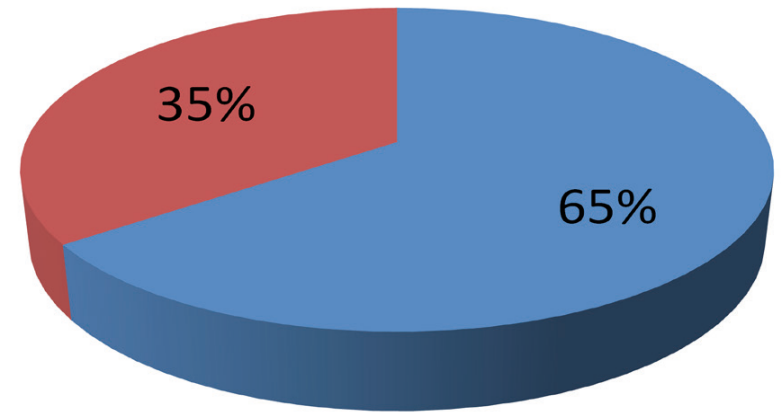

- Aplicação do presente do subjuntivo - Não aplicação

Fonte: (MORAES, 2014).

\footnotetext{
${ }^{14}$ Categorias estabelecidas pela investigadora para fins de análises como: se as atividades eram mais livres ou controladas; em que etapa da pesquisa foram aplicados os testes; tipos de atividades solicitadas; habilidade exigida, compreensão ou produção; e tipo de conjunção solicitada.
} 
Conforme observamos no gráfico, a aplicação do presente do subjuntivo foi superior, com 65\%, a não aplicação, com 35\%. Entretanto, é necessário observar que o índice de aplicação é geral, ou seja, é produto da soma dos índices referentes à frequência da regra em estudo ao longo das três etapas de coleta de dados. Isso significa que esses índices não nos permitem saber, por exemplo, se o índice do pré-teste foi maior do que os valores dos demais testes e vice-versa. Em função disso, a frequência geral não nos permite verificar os efeitos da IFF e a sua durabilidade. Portanto, a seguir, apresentamos de maneira discriminada a aplicação do presente do subjuntivo nos três tipos de testes.

\subsubsection{Variável etapa de coleta}

A variável etapa de coleta é utilizada para indicar o conhecimento prévio dos aprendizes a respeito da estrutura gramatical alvo, bem como os efeitos do tratamento instrucional e a sua durabilidade.

A seguir, na Tabela 1, apresentamos a variável etapa de coleta:

Tabela 1: Aplicação do presente do subjuntivo na variável etapa de coleta

\begin{tabular}{l|l|l|l}
\hline FATOR & APLIC.TOTAL & PERCENTAGEM & PESO RELATIVO \\
\hline Pré-teste & $66 / 478$ & 13 & 0,13 \\
\hline Pós-teste imediato & $467 / 520$ & 89 & 0,90 \\
\hline Pós-teste postergado & $456 / 508$ & 89 & 0,91 \\
\hline TOTAL & $989 / 1506$ & 65 & - \\
\hline
\end{tabular}

Input: 0,71; Signficance: 0,00

Fonte: (MORAES,2014).

$\mathrm{Na}$ Tabela 1, observamos que o fator pré-teste foi o que apresentou menor aplicação do presente do subjuntivo em espanhol em orações subordinadas. Por outro lado, os fatores pós-teste imediato e pós-teste postergado além de apresentarem índices praticamente idênticos foram os fatores que mais favoreceram a aplicação da forma verbal em estudo.

Durante a aplicação do pré-teste, os aprendizes não haviam sido submetidos à intervenção pedagógica, ou seja, não haviam participado do tratamento instrucional. Isso significa que a resolução dos testes esteve baseada no conhecimento prévio da estrutura gramatical pesquisada. Conforme observamos na tabela anterior, no pré-teste, de um total de 478 ocorrências, apenas 66 corresponderam à aplicação do presente do 
subjuntivo, ou seja, um percentual de $13 \%$, o que representa um baixo percentual em relação ao total de dados da primeira fase de coleta de dados. Acrescentamos a isso o fato de o peso relativo do pré-teste não ter-se mostrado relevante estatisticamente.

Percebemos também, na aplicação do pré-teste, uma forte sobreposição da correlação verbal do espanhol, como hipótese levantada na introdução deste trabalho, uma vez que os alunos, ao não entenderem corretamente o que precisavam fazer, utilizavam o mesmo tempo verbal, no caso o futuro imperfeito do espanhol, para tentar executar a tarefa, conforme o exemplo: $\mathrm{Me}$ casaré cuando encontraré el amor de mi vida. Contará la verdad cuando sabierá.

Quanto aos pós-testes, o pós-teste imediato foi aplicado no dia 25 de abril de 2013, imediatamente após a instrução explícita, enquanto que a execução da terceira fase da pesquisa, ou seja, a aplicação do pós-teste postergado, ocorreu no dia 13 de junho de 2013. Em outras palavras, a coleta de dados após a instrução explícita ocorreu em dois momentos distintos ao longo do tempo: o primeiro período de coleta serviu para indicar os efeitos do tratamento, enquanto que o segundo momento indicou a sua durabilidade. Conforme notamos na Tabela 1 , as duas últimas fases de aplicação dos testes obtiveram percentuais ( $89 \%$ ) praticamente idênticos, isto é, não houve alteração significativa da segunda etapa de dados em relação à terceira fase, no que diz respeito à aplicação do presente do subjuntivo do espanhol, em orações subordinadas, o que sugere aumento de percentual de aplicação da regra e a manutenção do seu índice de frequência.

Entretanto, se compararmos o índice de aplicação da regra do presente do subjuntivo da segunda etapa em relação à primeira fase de coleta de dados, podemos observar que houve um aumento significativo de aplicação, ou seja, uma diferença de $76 \%$. Esse resultado sugere que a instrução explícita resultou em efeitos benéficos à aplicação do presente do subjuntivo em espanhol, visto que houve aumento da aplicação dessa regra no pós-teste imediato. Em termos de índices de peso relativo, os fatores pós-teste imediato e postergado foram os que mais condicionaram a aplicação do presente do subjuntivo ao passo que o fator pré-teste foi o que menos motivou a sua aplicação. Esses índices reforçam a hipótese de que a instrução explícita se mostra favorável à aplicação da regra do presente do subjuntivo. Logo, os efeitos da instrução explícita foram concomitantemente benéficos e duráveis à aplicação do presente do subjuntivo em orações subordinadas. Em outras palavras, a IFF gerou efeitos benéficos à aplicação do presente do subjuntivo, os quais se mantiveram na última etapa de coleta de dados. 
Segundo Júnior (2010), "há efeitos positivos na instrução explícita e esses efeitos são duráveis” (p. 747). Em nosso estudo, podemos perceber que há uma durabilidade da regra entre o espaço de tempo das aplicaçóes dos testes imediato e postergado, pois os índices se mantiveram praticamente os mesmos.

A seguir, apresentamos exemplos de produçôes dos aprendizes deste estudo em relação ao uso correto do presente do subjuntivo, cuando, aunque e donde: "Cuando tu primo llegue, podremos irnos/ Hablaré nuevamente contigo cuando digas la verdad/Aunque haga los ejercicios, no los terminaré hoy/Aunque no vengas, iré a invitartel Te aconsejamos que vaya a donde digan tus profesores. Iré a donde estén todos".

A partir dos índices estatísticos e dos exemplos anteriores, percebemos os efeitos da intervenção explícita em relação ao uso correto do presente do subjuntivo.

Para finalizar, pudemos observar que houve aumento significativo estatisticamente entre a primeira etapa de coleta de dados e a segunda fase, o que sugere efeitos benéficos da instrução explícita no uso do presente do subjuntivo do espanhol em orações subordinadas. Além disso, constatamos que os benefícios instrucionais foram duráveis, ou seja, o índice de uso do presente do subjuntivo imediatamente após o tratamento instrucional, com valor de 0.90 , foi praticamente idêntico ao da terceira fase de coleta. Portanto, a instrução explícita, no que diz respeito ao uso do presente do subjuntivo, em espanhol, em orações subordinadas, produziu efeitos benéficos e duráveis.

Nessa variável, podemos observar os efeitos instrucionais ao longo do tempo. Entretanto, nessa variável não é possível distinguir os efeitos da instrução explícita na constituição de cada tipo de conhecimento linguístico. Em função disso, com o intuito de mensurar os efeitos da IFF no uso do presente do subjuntivo do espanhol em orações subordinadas como conhecimento explícito e implícito apresentamos a seguir a variável tipo de prática.

\subsubsection{Variável tipo de prática}

A variável tipo de prática serve para indicar os efeitos da instrução explícita na constituição da forma-alvo como tipo de conhecimento.

Entendemos por atividades controladas todas aquelas tarefas pelas quais podemos monitorar a execução, ou seja, o aprendiz tem de executar uma tarefa com questões preestabelecidas. Por atividades livres, entendemos 
que os aprendizes têm total autonomia em sua execução, sem controle quanto ao número de questões e ao uso da regra-alvo. Em outras palavras, nas atividades controladas, verificamos o uso do objeto em estudo e podemos administrá-lo e na prática livre os alunos são mais autônomos quanto à execução da tarefa e ao uso da forma-alvo.

Segundo Ellis (2006), atividade controlada pressupõe conhecimento explícito, enquanto que atividade livre indica conhecimento implícito.

A seguir, na Tabela 2, podemos verificar a aplicação do presente do subjuntivo em atividades controladas e livres, ou seja, respectivamente, como conhecimento implícito e explícito.

Tabela 2: Aplicação do presente do subjuntivo na variável tipo de prática

\begin{tabular}{l|l|l|l}
\hline FATOR & APLIC.TOTAL & PERCENTAGEM & PESO RELATIVO \\
\hline Controlada & $637 / 981$ & 64 & 0,71 \\
\hline Livre & $352 / 525$ & 67 & 0,74 \\
\hline TOTAL & $989 / 1508$ & 65 & - \\
\hline
\end{tabular}

Input: 0,65; Signficance: 0,42

Fonte: (MORAES, 2014).

$\mathrm{Na}$ Tabela 2, podemos observar que a produtividade do subjuntivo em orações subordinadas do espanhol foi maior em práticas livres (de 0,74) do que em práticas controladas $(0,71)$. Em outras palavras, de um total de 525 ocorrências em práticas livres, 352 corresponderam à aplicação da regra, ou seja, 67\%, enquanto que, na prática controlada, de 981 ocorrências, 637 foram produto da aplicação da regra em estudo, ou seja, 64\%.

Entretanto, podemos observar, por meio dos índices de peso relativo, que apesar de haver um sutil favorecimento (de 3\%) à produtividade da regra na prática livre, ambos os tipos de prática se mostraram estatisticamente significativos.

Segundo Ellis (2005b), quando o resultado da aprendizagem é verificado por meio de testes de respostas livres parece que o ensino da forma tem um efeito mais reduzido, já que este instrumento é inferior em número à metade daquele produzido no caso dos testes de respostas fechadas/ controladas, por exemplo, respostas de seleção múltipla.

Ainda que o número de ocorrências da prática controlada (981) seja superior (525) ao da prática livre, no cômputo total de cada tipo de prática, a prática livre se mostrou mais favorável à aplicação do presente 
do subjuntivo, ou seja, a instrução explícita motivou mais o uso da regraalvo como conhecimento implícito do que como conhecimento explícito. Entretanto, em virtude de a diferença em peso relativo não ser tão expressiva, não podemos deixar de assinalar o papel do tratamento na constituição do uso do presente do subjuntivo como conhecimento explícito.

Como observamos anteriormente, embora a maioria das atividades privilegiou o conhecimento explícito em número de ocorrências, percebemos que os alunos conseguiram utilizar corretamente o presente do subjuntivo em atividades livres, que privilegiavam o conhecimento implícito.

Segundo Dekeyser (2003), "aprendizado sem consciência do que está sendo aprendido" (p. 314), e aprendizado explícito: "ensino de regra gramatical, quando os alunos são estimulados a encontrar regras por si próprios" (p. 314).

A título de exemplo, apresentamos o excerto 1 referente à produção do aprendiz com o intuito de visualizarmos indícios de conhecimento implícito: "Bueno creo que logre vivir solol es probable que encuentre muchos amigos".

Neste caso, percebemos que o aluno utiliza o presente do subjuntivo corretamente, mas com outras conjunções que não o foco deste estudo. Nesse sentido, podemos perceber o uso espontâneo por parte do aluno ao produzir a história solicitada na atividade, tipo de emprego característico do conhecimento implícito.

Por outro lado, como exemplo de conhecimento explícito, apresentamos o excerto 2, a seguir: "cuando necessite / aunque no se sienta". Nesse caso, o aluno já se mostra consciente quanto ao uso do subjuntivo nas orações temporais com cuando e concessivas com aunque. Como se tratava de uma atividade de produção textual, o aluno precisou recorrer à regra gramatical do presente do subjuntivo do espanhol, a qual foi ensinada nas aulas tratamento.

Nesse sentido, corroboramos com as ideias de Dekeyser (2003), que sugere que há um papel positivo para a atenção à forma e para o aprendizado explícito, pois os alunos estarão verificando pontualmente como o presente do subjuntivo deve ser utilizado e em que ocasióes especificamente.

Segundo Doughty e Williams (1998), no que tange ao conhecimento explícito, três aspectos devem ser levados em conta: (1) antes dos aspectos linguísticos, o aprendiz deve trabalhar com o sentido e é necessário que haja a certificação de que as formas-alvo sejam pelo menos naturais para que a tarefa possa ser completada; (2) os aspectos linguísticos devem ser escolhidos 
por meio de uma análise das necessidades dos aprendizes, feita de maneira reativa e proativa e (3) o tratamento deve ser breve e evidente. Podemos perceber esses três critérios nas seguintes passagens selecionadas no pós-teste imediato oral e escrito: para o aspecto (1) podemos citar como exemplo: "sí... busco un aparcamiento donda.... donde tenga una playa......pierto". Nesse caso, podemos perceber que o informante trabalha literalmente com o sentido para responder. Não sabemos se ele entendeu o sentido da palavra "apacarcamiento" como estacionamento realmente, ou se interpretou como apartamento, como muitos outros alunos fizeram. O que acontece é que, estabelecendo o sentido para si, pôde responder corretamente utilizando o presente do subjuntivo.

Para o aspecto (2), utilizamos uma resposta da atividade de múltipla escolha: "Cuando salga el sol, será muy bueno para ir a la montaña". Como se tratava de múltipla escolha, os alunos tinham a possibilidade de eleger, por meio de análise, qual a melhor palavra completaria o espaço. Percebemos que, após as aulas tratamento, os alunos tiveram muito mais autonomia e segurança na escolha e aplicação do presente do subjuntivo.

Mas, percebemos também que em alguns momentos queriam utilizar o presente do subjuntivo quando este não poderia ser utilizado, como por exemplo: "cuando llegues allá vaya percibir". Podemos perceber neste enunciado uma hipercorreção, pois o informante utiliza corretamente o presente do subjuntivo com a conjunção cuando, mas também o utiliza com o verbo "vaya", que, neste caso, exigiria o uso do presente do indicativo. $\mathrm{Ou}$ seja, no desejo de acertar sempre e já sabendo que o objeto de estudo era o presente do subjuntivo, o participante utiliza sempre o verbo conjugado no subjuntivo, o que nos permite concluir como um facilitador de aquisição, pois o aprendiz aciona códigos semelhantes para tentar processar corretamente o verbo em espanhol.

Para o aspecto (3), podemos utilizar os resultados finais, pois como o tratamento aconteceu em duas aulas, é possível dizer que foi um tratamento rápido e que obteve resultados, pois os alunos mantiveram uma percentagem alta nos resultados dos pós-teste imediato e pós-teste postergado.

Ao longo das análises, encontramos usos de outras conjunções, que não as do objeto de estudo, e podemos notar que várias situações expostas pelos alunos estão de acordo com Norris e Ortega (2000), ou seja, quando nem a apresentação da regra, nem as direçóes atenderem às formas particulares de um tratamento, aquele tratamento será considerado implícito. Ou seja, 
embora este estudo privilegie a instrução explícita, percebemos que nas atividades livres os participantes fizeram uso da instrução implícita.

Isso fica visível quando os informantes utilizam o presente do subjuntivo corretamente, mas não com as conjunções objeto deste estudo. Podemos citar como exemplos alguns casos das atividades de produção escrita e oral: "es posible que sea bien recibidol es importante que aproveches el viajel para que hables/ creo que hasta el final de semana estén liberados/ Así que procure un profesor que le ayude". Nesse sentido, fica evidente o bom uso do presente do subjuntivo.

Em resumo, os efeitos instrucionais favoreceram a aplicação do presente do subjuntivo do espanhol em orações subordinadas em ambos os tipos de conhecimento linguístico, com um sutil favorecimento em prol do uso desse aspecto linguístico como conhecimento implícito, com peso relativo de 0.74 .

A seguir, trataremos acerca da variável tipo de atividade.

\subsubsection{Variável tipo de atividade}

A variável tipo de atividade caracteriza-se pela escolha, pelo planejamento e pela execução das atividades pensadas para a pesquisa.

Nesta seção, apresentaremos os resultados em relação ao tipo de atividades. Essas atividades foram pensadas juntamente com a professora titular da turma e julgamos que dão conta do uso do presente do subjuntivo, uma vez que mesclam uso controlado, principalmente nas atividades de múltipla escolha e preenchimento de lacunas, e uso livre, nas atividades de descrição de imagens e criação de histórias.

Tabela 3: Aplicação do presente do subjuntivo na variável tipo de atividade

\begin{tabular}{l|l|l|l}
\hline FATOR & APLIC.TOTAL & PERCENTAGEM & PESO RELATIVO \\
\hline Múltipla escolha & $199 / 287$ & 69 & 0,77 \\
\hline Preenchimento de lacunas & $215 / 334$ & 64 & 0,73 \\
\hline Descrição de imagens & $75 / 157$ & 47 & 0,59 \\
\hline Respostas controladas & $271 / 362$ & 74 & 0,72 \\
\hline Criação de história & $229 / 137$ & 62 & 0,72 \\
\hline
\end{tabular}

Input: 0,66; Signficance: 0,00

Fonte: (MORAES, 2014). 
$\mathrm{Na}$ Tabela 3, podemos observar que o fator descrição de imagens apresentou menor índice de aplicação da regra, ao passo que os fatores resposta controlada, criação de história e preenchimento de lacuna apresentaram índices praticamente idênticos. Entretanto, é válido destacarmos que o teste múltipla escolha apresentou produtividade da regra. Considerando que os fatores múltipla escolha, preenchimento de lacuna e resposta controlada aludem à prática controlada e, portanto, ao conhecimento explícito, ao passo que descrição de imagens e criação de histórias remetem à prática livre conhecimento implícito, parece haver maior favorecimento da regra-alvo nas três atividades de conhecimento explícito.

Nosso estudo concorda com as ideias de Norris e Ortega (2001) e de Ellis $(2006,2009)$, pois preconiza a utilização das atividades focadas, uma vez que ofereceram oportunidades para a comunicação, utilizando um aspecto específico da língua, no caso o presente do subjuntivo. Ao pensarmos atividades focadas, estamos contemplando os quatro critérios: uso natural da língua-alvo; concentração; foco na forma; tipo de atividades.

Em relação ao pré-teste imediato e ao pós-teste postergado, precisamos destacar a criação de história, pois, se tratando de uma atividade livre, podemos dizer que foi satisfatória a aplicabilidade do presente do subjuntivo, uma vez que os informantes conseguiram utilizá-lo inclusive com outras conjunçôes como: "Es posible que extrañe un pocol es posible que sea bien recebido/ Asi que llegues/ para que puedas/ es necesario para que crezca y seal Es importante que cuentes/ Debes estar en un lugar que te sientas confortable".

Podemos perceber que os informantes conseguem aplicar a regra, mesmo sem ter estudado explicitamente essas conjunçôes, o que nos faz pensar que possa haver sim uma relação com e uma influência da LM, pois muitas dessas situações o aprendiz vivencia em português e faz uso também do presente do subjuntivo, como por exemplo: "É possível que você estranhe um pouco; para que possas; é necessário que cresça”.

Mas, quando o informante utiliza: "Debes estar en un lugar que te sientas confortable", podemos fazer alusão ao uso inconsciente do presente do subjuntivo com o pronome relativo donde, uma vez que tal pronome está implícito dentro do enunciado: "debes estar en un lugar donde te sientas confortable". Acreditamos que os alunos inconscientemente estejam começando a fazer associações de uso e estabelecendo relações de sentido nos enunciados. 
Em relação às atividades criação de história e descrição de imagens, podemos verificar as ideias e definições de Ellis (2009), as quais podemos encontrar ao analisar a Tabela 3: o foco primário deve ser no "significado" (os aprendizes devem estar interessados principalmente no processamento do significado semântico e pragmático das falas); deve haver algum tipo de lacuna (exemplo, uma necessidade de transmitir informação, expressar uma opiniāo ou inferir significado); os aprendizes devem confiar nos seus próprios recursos (linguístico e não linguístico) a fim de realizar a atividade; há um resultado definido claro, além do uso da língua. Ou seja, os participantes estavam interessados em estabelecer uma comunicação efetiva e que a mesma pudesse transmitir uma informação correta. Para isso, estes passaram a confiar mais em seus recursos linguísticos e no uso do presente do subjuntivo em espanhol para poder executar a tarefa, alcançando, dessa forma, uma melhora considerável no pós-teste imediato e no pós-teste postergado.

Com a intenção de verificarmos se o uso do subjuntivo é mais produtivo em práticas controladas do que livres, optamos por amalgamar, isto é, reunir os fatores a partir da natureza da atividade: prática livre (criação de histórias e descrição de imagens) e prática controlada (múltipla escolha, preenchimento de lacunas e respostas controladas), conforme podemos verificar na tabela a seguir:

Tabela 4: Uso do presente do subjuntivo amalgamado entre prática controlada e prática livre

\begin{tabular}{l|l|l|l}
\hline FATOR & APLIC.TOTAL & PERCENTAGEM & PESO RELATIVO \\
\hline Práticas controladas & $644 / 990$ & 65 & 0,73 \\
\hline Prática livre & $346 / 519$ & 66 & 0,69 \\
\hline Total & $989 / 1506$ & 65 & - \\
\hline
\end{tabular}

Fonte: (MORAES, 2014).

Podemos perceber que, embora os alunos tenham obtido um melhor resultado na prática controlada, o número de atividades propostas e o número de dados obtidos na prática livre foram inferiores, o que nos demonstra que o resultado é praticamente o mesmo e nos faz acreditar que o conhecimento explícito da forma presente do subjuntivo converteu-se em alguns momentos em um conhecimento implícito, pois o informante conseguiu utilizar a regra sem perceber que a estava utilizando. Conforme Dekeyser (2003), 
[...] apesar de o conhecimento adquirido implicitamente tender a permanecer implícito, e o conhecimento adquirido explicitamente tender a permanecer explícito, o conhecimento aprendido explicitamente pode tornar-se implícito no sentido que aprendizes podem perder a consciência das estruturas com o tempo, e aprendizes podem tornar-se conscientes de estruturas do conhecimento implícito ao tentarem acessá-lo, por exemplo, ao aplicá-lo a um novo contexto ou transmiti-lo verbalmente a uma outra $\operatorname{pessoa}^{15}$ (p. 315).

Nesse sentido, podemos dizer que ambos os tipos de atividades, controladas e livres, foram favoráveis à aplicação da regra e acreditamos que não é bom postergar o insumo a estruturas subordinadas, principalmente no caso do objeto em estudo e uma vez que em ambas práticas (controlada e livre) os alunos conseguiram êxito em suas construções e usos.

A seguir, os resultados da variável tipo de habilidade, na qual verificamos o fator de compreensão e produção dos informantes.

\subsubsection{Variável tipo de habilidade}

A variável tipo de habilidade está constituída por atividades que exigiam dos participantes uma maior compreensão no uso ou não do presente do subjuntivo em espanhol e a capacidade de produção do mesmo objeto de estudo.

Verificar o nível de compreensão e a capacidade de produção dos alunos quanto ao uso do presente do subjuntivo em espanhol, em especial com cuando, aunque e donde, foi um dos fatores que nos ajudou a encontrar resultados precisos e satisfatórios.

A Tabela 5 expõe dados referentes à variável tipo de habilidade.

15 "even though implicitly acquired knowledge tends to remain implicit, and explicitly acquired knowledge tends to remain explicit, explicitly learned knowledge can become implicit in the sense that learners can lose awareness of its structures over time, and learners can become aware of the structures of implicit knowledge when attempting to Access it, for example for applying it to a new context $r$ conveying it verbally to somebody else". 
Tabela 5: Aplicação do presente do subjuntivo na variável tipo de habilidade

\begin{tabular}{|l|l|l|l|}
\hline FATOR & APLIC.TOTAL & PERCENTAGEM & PESO RELATIVO \\
\hline Compreensão & $199 / 287$ & 69 & 0,73 \\
\hline Produção & $790 / 1219$ & 64 & 0,72 \\
\hline TOTAL & $989 / 1506$ & 65 & \\
\hline
\end{tabular}

Input: 0,65; Signficance: 0,15

Fonte: (MORAES, 2014).

Podemos verificar que os índices foram praticamente idênticos em se tratando da habilidade de compreensão e de produção, ou seja, nossos informantes conseguiram compreender a função do presente do subjuntivo assim como conseguiram produzir utilizando corretamente o objeto de estudo, embora vejamos que o maior número de ocorrência tenha acontecido nas atividades de produção.

Observamos que embora as atividades de produção sejam consideradas livres, havia espaço para o uso ou não do presente do subjuntivo em espanhol, isto é, as atividades propiciavam as condiçóes necessárias para o uso do objeto de estudo.

Reiteramos que entendemos por atividades livres as tarefas de criação de história e de descrição de imagens, e por atividades controladas as atividades de múltipla escolha, preenchimento de lacunas e respostas controladas.

Acreditamos que os resultados tenham sido praticamente idênticos, uma vez que as atividades eram livres, então os alunos se sentiram à vontade para utilizarem quantas vezes acreditassem necessário o presente do subjuntivo em espanhol.

Nesse sentido, percebemos que muitos informantes utilizaram o conhecimento prévio para compreender e dar prosseguimento no enunciado, como nos casos a seguir: "Busco un aparcamiento donde pueda acostarmel Busco un aparcamiento donde sea seguro para mis hijos/Busco un aparcamiento donde pueda mirar el mar/ Busco un aparcamiento donde sea feliz".

Percebemos que os alunos utilizam corretamente o presente do subjuntivo, mas, ao acionarem seus conhecimentos prévios, verificamos que esses estudantes podem ter compreendido erroneamente o sentido da frase, uma vez que podem ter interpretado a palavra "aparcamiento" como 
"apartamento" e não "estacionamento" em português. Identificamos, no entanto, que a compreensão equivocada da palavra não prejudicou o uso correto do objeto em questão, no caso o presente do subjuntivo em espanhol.

Podemos perceber o fato de arriscar-se e que há certa autonomia nos seguintes trechos: "Creo que debes contar el secreto cuando tengas ganas, cuando te sientas bien. Deberás estar en un lugar donde sea tranquilo y solo lo cuentes si es alguien que confies. Aunque lo cuentes no te pasará nada. Además nadie sabe cuando esto se pasó. Sobre las consecuencias, no sé porque tampoco sé cual es el secreto". Evidencia-se que a escrita do informante flui normalmente, inclusive arrisca-se ao utilizar duas vezes o pronome complemento "lo". A escrita parece ser natural, pois, ao final, ainda brinca com a atividade, dizendo que não sabe quais as consequências, pois não sabe de que segredo se trata. Sentimos uma naturalidade e certa facilidade na escrita, inclusive quando utiliza os objetos de estudo em questão, cuando, aunque e donde.

Pode-se dizer, dessa forma, que essa facilidade agrega valor à intervenção por meio da IFF, uma vez que no pré-teste muitas eram as dúvidas quanto ao uso do presente do subjuntivo e, agora, nas etapas de pós-teste imediato e pós-teste postergado, podemos verificar certa autonomia dos participantes na utilização da forma verbal.

Para melhor verificarmos os dados, optamos por realizar um cruzamento entre algumas variáveis, como podemos verificar nas tabelas a seguir:

Tabela 6: Cruzamento tipo de atividade e tipo de habilidade

\begin{tabular}{|l|l|l|l|l|l|}
\hline Fatores & $\begin{array}{l}\text { Múltipla } \\
\text { escolha }\end{array}$ & $\begin{array}{l}\text { Preenchimento } \\
\text { de lacunas }\end{array}$ & $\begin{array}{l}\text { Descrição de } \\
\text { imagem }\end{array}$ & $\begin{array}{l}\text { Respostas } \\
\text { controladas }\end{array}$ & $\begin{array}{l}\text { Criação de } \\
\text { história }\end{array}$ \\
\hline Compreensão & $199 / 287=69 \%$ & & & & \\
\hline Produção & & $215 / 334=64 \%$ & $75 / 157=48 \%$ & $271 / 362=75 \%$ & $229 / 366=63 \%$ \\
\hline
\end{tabular}

Fonte: (MORAES, 2014).

Verificamos que a menor porcentagem de uso do presente do subjuntivo se dá com a atividade de produção "descrição de imagem". Isso não quer dizer que seja menor o índice de acertos, pois podemos verificar que há um número menor de ocorrências do objeto de estudo, ou seja, somente 157 ocorrências, enquanto na atividade de compreensão "múltipla escolha" foram 287 ocorrências do uso do presente do subjuntivo com as conjunções cuando e aunque e com o pronome relativo donde. Na atividade de respostas 
controladas, obtivemos um total de 362 ocorrências com uso do presente do subjuntivo.

Nota-se, assim, o quanto a aula tratamento produziu efeitos favoráveis, pois, das 362 ocorrências, tivemos um percentual de acertos de $75 \%$, ou seja, 271 respostas corretas, um índice muito alto se tratando de uma atividade na qual os alunos podiam escolher o que escrever ou dizer e utilizar a forma verbal em estudo ou outra.

Nesse sentido, podemos dizer que em todas as atividades do pós-teste imediato e pós-teste postergado os informantes mantiveram um índice alto de acertos.

A seguir, realizamos outro cruzamento, entre tipo de prática e tipo de habilidade.

Tabela 7: Cruzamento tipo de prática e tipo de habilidade

\begin{tabular}{l|l|l}
\hline Fatores & Controlada & Livre \\
\hline Compreensão & $199 / 287=69 \%$ & - \\
\hline Produção & $438 / 694=63 \%$ & $352 / 525=67 \%$ \\
\hline
\end{tabular}

Fonte: (MORAES, 2014).

Percebemos que os índices são muito próximos, $63 \%$ em práticas de produção controlada, $67 \%$ em produção livre e $69 \%$ em atividades de compreensão controlada, embora tenhamos um maior número de ocorrências em atividades de produção (438/694). Acreditávamos que as ocorrências seriam menores em atividades de prática livre, pois pensávamos que teríamos mais dificuldade em obter dados (NORRIS; ORTEGA, 2001) quanto ao uso do presente do subjuntivo em espanhol, mas, para nossa surpresa, ocorreu exatamente o oposto. Nas atividades livres, os participantes demonstraram maior autonomia e liberdade para descreverem imagens e criarem histórias utilizando o presente do subjuntivo em espanhol.

$\mathrm{Na}$ próxima subseção, abordaremos mais especificamente as conjunções objetos de estudo desta tese: cuando, aunque e donde.

\subsubsection{Variável tipo de conjunção}

A variável tipo de conjunção refere-se especificamente ao uso do presente do subjuntivo em espanhol e ao grupo de fatores conjunçóes. Esse grupo de fatores está constituído por: cuando, aunque, donde e outras conjunções. 
Sabíamos que, nas produções livres, os alunos poderiam utilizar outras conjunções, como o fizeram e está demonstrado na tabela que segue:

Tabela 8: Aplicação do presente do subjuntivo na variável tipo de conjunção

\begin{tabular}{|l|l|l|l|}
\hline FATOR & APLIC.TOTAL & PERCENTAGEM & PESO RELATIVO \\
\hline Cuando & $311 / 456$ & 68 & 0,79 \\
\hline Aunque & $298 / 498$ & 59 & 0,66 \\
\hline Donde & $244 / 377$ & 64 & 0,65 \\
\hline Outras Construções & $136 / 175$ & 77 & 0,81 \\
\hline TOTAL & $989 / 1506$ & 65 & \\
\hline
\end{tabular}

Input: 0,65; Signficance: 0,00

Fonte: (MORAES, 2014).

Percebemos que o menor percentual se dá com a conjunção aunque (59\%) e o maior com outras conjunções (77\%), mas temos de levar em consideração que o número de ocorrências de subjuntivo com aunque é maior (498) do que o número de ocorrências com outras conjunções (175).

Podemos perceber o uso adequado do presente do subjuntivo, principalmente em se tratando da conjunção cuando (311/456), uma vez que no pré-teste era a conjunção com a qual acontecia o maior número de erros. No pré-teste, a grande maioria dos alunos utilizava verbos no infinitivo para falar de um futuro próximo.

Se voltarmos à tabela da etapa de coleta, fica visível o aumento do índice de acertos dos alunos, uma vez que, no pré-teste, houve apenas 66 acertos entre 478 ocorrências. Após o tratamento, com aulas do presente do subjuntivo com foco na forma e instrução explícita, esse índice alcança 467 acertos de 520 ocorrências no pós-teste imediato e o índice de acertos é praticamente mantido, 456 de 508 ocorrências, no pós-teste postergado.

Com a finalidade de realizarmos uma análise mais apurada, resolvemos cruzar os dados do tipo de atividade X tipo de conjunção: 
Tabela 9: Cruzamento tipo de atividade e tipo de conjunção

\begin{tabular}{l|l|l|l|l|l}
\hline Fatores & $\begin{array}{l}\text { Múltipla } \\
\text { escolha }\end{array}$ & $\begin{array}{l}\text { Preenchimento } \\
\text { de lacunas }\end{array}$ & $\begin{array}{l}\text { Descrição } \\
\text { de imagem }\end{array}$ & $\begin{array}{l}\text { Respostas } \\
\text { controladas }\end{array}$ & $\begin{array}{l}\text { Criação de } \\
\text { histórias }\end{array}$ \\
\hline Cuando & $71 / 96=74 \%$ & $71 / 105=68 \%$ & $26 / 51=51 \%$ & $57 / 78=73 \%$ & $86 / 126=68 \%$ \\
\hline Aunque & $70 / 107=65 \%$ & $68 / 120=57 \%$ & $23 / 52=44 \%$ & $58 / 84=69 \%$ & $79 / 135=59 \%$ \\
\hline Donde & $58 / 84=69 \%$ & $76 / 109=70 \%$ & $21 / 41=51 \%$ & $26 / 41=63 \%$ & $63 / 102=62 \%$ \\
\hline $\begin{array}{l}\text { Outras } \\
\text { construçôes }\end{array}$ & & & $5 / 13=38 \%$ & $130 / 159=82 \%$ & $1 / 3=33 \%$ \\
\hline
\end{tabular}

Fonte: (MORAES, 2014)

Nessa tabela, podemos perceber que o menor índice de acertos acontece com a conjunção aunque (44\%) e o maior com a conjunção cuando (74\%), o que vai ao encontro de nossas hipóteses levantadas anteriormente, ou seja, os alunos perceberam o equívoco ao utilizarem o infinitivo com a conjunção cuando, e, a partir das aulas tratamento, passam a utilizar o tempo verbal corretamente com a conjunção em questão. Não podemos dizer, contudo, que os alunos continuem utilizando equivocamente o presente do subjuntivo com a conjunção aunque.

Podemos confirmar a hipótese já descrita na introdução deste trabalho de que os alunos tenham supergeneralizado a regra, ou seja, tenham ido pela regra de conjugação da conjugação do verbo ser no presente do subjuntivo do espanhol: sea, seas... e tenham utilizado a mesma conjugação para outros verbos, como por exemplo o verbo estar: estea, esteas.

Notamos que o índice menor se deve, também, ao fato de haver menos ocorrências de uso (23/52) na atividade de descrição de imagem. O mesmo acontece com a conjunção donde (21/41) e até mesmo com cuando (26/51) nessa mesma atividade.

O fato é que podemos dizer que há um uso adequado do presente do subjuntivo em todos os tipos de atividade e em todos os tipos de conjunçôes, chegando a alcançar um índice de 71 acertos em 96 ocorrências, ou seja, um percentual de $74 \%$ de acerto na atividade de múltipla escolha, o que demonstra realmente que a instrução explícita, mais especificamente o ensino com foco na forma, é favorável para o aprendizado de gramática em língua estrangeira.

Nessa perspectiva, reiteramos nosso estudo com as ideias de Spada (1997a), que define o ensino de foco na forma como qualquer esforço 
pedagógico utilizado pelo professor para chamar a atenção do aluno para a forma específica, no caso deste estudo, no uso de cuando, aunque e donde, de maneira explícita.

Concordamos com a ideia da autora de que também podemos ensinar gramática através do ensino direto da língua, como, por exemplo, do ensino de regras gramaticais - o que aconteceu neste estudo e que nos permitiu verificar os resultados alcançados.

Assim, para finalizar esta subseção, realizamos o cruzamento de dados entre tipo de prática $\mathrm{X}$ tipo de conjunção:

Tabela 10: Cruzamento tipo de prática e tipo de conjunção

\begin{tabular}{|l|l|l|}
\hline Fatores & Controlada & Livre \\
\hline Cuando & $225 / 324=69 \%$ & $86 / 132=65 \%$ \\
\hline Aunque & $214 / 359=60 \%$ & $84 / 139=60 \%$ \\
\hline Donde & $197 / 295=67 \%$ & $47 / 82=57 \%$ \\
\hline
\end{tabular}

Fonte: (MORAES, 2014).

Podemos perceber que o índice de uso do presente do subjuntivo é considerado adequado com todos os objetos de estudo desta tese (cuando, aunque e donde), pois o menor índice de acertos acontece com o pronome donde (57\%), na prática livre, e o maior acontece com a prática controlada e com a conjunção cuando (69\%).

Em relação às outras construções, em atividade de prática livre, percebemos que os participantes utilizaram adequadamente o presente do subjuntivo em 135 ocorrências, ou seja, 78\%. Isso demonstra que, mesmo com outras conjunções, os alunos estavam aptos a utilizar o presente do subjuntivo.

Quanto ao uso de donde, acreditamos que os informantes tenham utilizado o menor número possível, pois têm certo receio, ainda, em utilizar elementos circunstanciadores dentro de um enunciado, o que não acreditamos que aconteça com a conjunção cuando e donde, pois são elementos que, muitas vezes, podem introduzir as frases. Podemos perceber que em alguns momentos os alunos não utilizam o pronome donde, mas ele está implícito dentro do enunciado, conforme a seguinte passagem: "Escoja 
un lugar que sea tranquilo para hablar", bem como também encontramos, várias vezes, as conjunções cuando e donde iniciando frases: "Cuando llegue en Españal Aunque sea difícill Aunque no encuentres/ Aunque podamos/ Cuando tenga duda".

Reiteremos as ideias de Spada (1997b), pois impulsionamos todos os esforços para chamar a atenção do aluno para a forma específica, no caso o presente do subjuntivo em espanhol.

\section{Considerações finais}

Este estudo buscou contribuir para a Área de Linguística Aplicada e para o ensino de LE, mais especificamente o ensino do presente do subjuntivo em espanhol, tendo como base a IFF. A partir da proposta, de procedimentos metodológicos e da análise e discussão dos dados, evidenciouse o quão benéfica foi a IFF para a aquisição do presente do subjuntivo no uso e aplicação das conjunções cuando e aunque e com o pronome relativo donde.

Para a perspectiva teórica recorreu-se à teoria de Spada (1997a e b) em razão de que a perspectiva teórica da IFF nos deu subsídios para um trabalho mais detalhado e consistente com os participantes, uma vez que verificamos que o trabalho com a língua pode se dar diretamente, através do ensino direto da língua, com atividades gramaticais específicas e explícitas.

Ellis $(2001,2006,2009)$ nos mostrou que o trabalho no ensino de gramática pode ser planejado, e que através de práticas controladas e intensivas é possível obter um bom resultado no ensino.

Norris e Ortega $(2000,2001)$ contribuíram para a elaboração e execução das tarefas e atividades propostas. Os autores categorizaram medidas de resultados importantes e, a partir disso, pudemos elaborar nossos testes: pré-teste, pós-teste imediato e pós-teste postergado.

Percebemos, portanto, que após a aplicação dos testes e análise dos resultados obtidos, o quanto a intervenção pedagógica, com base na IFF, foi importante para a obtenção dos resultados.

\section{Referências}

ANDRÉ, M. E. Etnografia da prática escolar. 11ª ed. São Paulo: Papirus, 2004. BOÉSSIO, C. P. D. A transferência indevida do infinitivo flexionado no ensino do espanhol para brasileiros. Dissertação de mestrado. Universidade Católica de Pelotas, 2003. 
COSTA. G. V. M. O uso do presente do modo subjuntivo em lingua espanhola: contribuição para aprendizes brasileiros. Católica de Pelotas: dissertação de mestrado, 2004.

DEKEYSER, R. Learning second language grammar rules: An experiment with a miniature linguistic system. Studies in Second Language Acquisition, 17, p. 379410, 1995.

DEKEYSER, R. Beyond focus on form: Cognitive perspective on learning and practicing second language grammar. In: DOUGHTY, C. \& Williams, J. (Eds.), Focus on form in classroom second language acquisition (p.42-63). 1998. New York: Cambridge University Press.

DEKEYSER, R. Implicit and explicit learning. In: DOUGHTY, C. J.; LONG, M. $\mathrm{H}$ (Eds.), The handbook of second language acquisition. Oxford, Massachusetts e Victoria: Blackwell. Publishing, Chap. 11, p.313-348, 2003.

DOUGHTY, C; WILLIAMS, J. Focus on Form in Classroom Second Language Acquisition. Cambridge University Press, 1998.

EDMODO. Disponível em: www.edmodo.com. Acesso em: 31 out. 2012.

ELLIS, R. Second language acquisition. Oxford, Oxford University Press, 1997.

ELLIS, R. Introduction: investigating form-focused instruction. Language Learning 51: Supplement 1. Form-focused instruction and second language learning, p. 1-46, 2001.

ELLIS, R. Measuring implicit and explicit knowledge of a second language: a psychometric study.Studies in Second Language Acquisition 27, p. 141-72, 2005 b. ELLIS, R. Current issues in the teaching off grammar. An SLA perspective. TESOL Quartely, 40 (1), 83-107, 2006.

ELLIS, R. Task-based language teaching: sorting out the misunderstandings. International Journal of Applied Linguistics, v.19, n.3, p. 221-246, 2009.

JÚNIOR, Ronaldo Mangueira Lima. Uma investigação dos efeitos do ensino explícito da pronúncia na aula de inglês como língua estrangeira. RBLA, Belo Horizonte, v.10, n.3, p. 747-771, 2010.

LIMA, M. S.; BORBA, F. R. O professor de língua estrangeira e sua visão do tratamento do erro. In: ROTTAVA, L.; LIMA, M. S. (Orgs.). Linguística Aplicada: relacionando teoria e prática no ensino de línguas. Ijuí: Unijuí, p.224-266, 2004.

LITTLEWOOD. W. La enseñanza comunicativa de idiomas. Cambridge: Madrid, 1996.

MITCHELL, R.; MYLES, F. \& MARSDEN, E. Second language learning theories. Third Edition. London: Routledge, 2013. 
NORRIS, J. \& ORTEGA, L. Effectiveness of L2 instruction: A research synthesis and quantitative meta-analysis. Language Learning, 50, p. 417-528, 2000.

NORRIS, J. \& ORTEGA, L. Does Type of Instruction Make a Difference? Substantive Findings From a Meta-analytic Review. In: Language Learning. Supplement 1: form-focused instruction and second language learning, p. 157213, 2001.

ROEHR, K. Linguistic and metalinguistic categories in second language learning. Cognitive Linguistics 19, p. 67-106, 2008.

SANKOFF, D.; TAGLIAMONTE, S. A.; SMITH, E. Goldvarb X. A multivariate analysis application. Toronto: Departament Linguistic; Ottawa: Departament of Mathematics, 2005.

SPADA, N. Form-focused instruction and second language acquisition: A review of classroom and laboratory research. Language Teaching, 30,p. 1-15, 1997a.

SPADA, N. Form - focused instruction and second language acquisition: A review of classroom and laboratory research. Language Teaching, 30, p. 73-87, 1997b.

SPADA, N. e LIGHTBOWN, P. Form- focused instruction: isolated or integrated. Tesol Quarterly, v. 42, n.2, p. 181-207, 2008.

SPADA, N.; TOMITA, Y. Interactions Between Type of Instruction and Type of Language Feature: A Meta-Analysis.Language Learning 60:2, p.263-308, June 2010.

TAGLIAMONTE, S. Analysing Sociolinguistic Variation. Cambridge: Cambridge University Press, 2006.

TEAM SPEAK. Disponível em: http://www.teamspeak.com/?page=teamspeak3. Acesso em: 30 mar. 2013.

VILLALBA, T. K. B. Pepe vio que no tiene jeito, su mujer es asi mismo: as delicadas relaçôes lexicais entre a L1 e a L2 na aquisição de español por universitarios brasileiros. Tese doutorado, UFRGS. Porto Alegre, 2002.

Data de submissão: 24/06/15. Data de aprovação: 23/09/15. 